\title{
Measurement of human cerebral monoamine oxidase type B (MAO-B) activity with positron emission tomography (PET): a dose ranging study with the reversible inhibitor Ro 19-6327
}

\author{
C.J.Bench ${ }^{1}$, G.W.Price², A.A.Lammertsma², J.C.Cremer ${ }^{2}$, S.K.Luthra ${ }^{2}$, D. Turton ${ }^{2}$, R. J.Dolan ${ }^{1}$, R. Kettler ${ }^{3}$, \\ J. Dingemanse ${ }^{3}$, M. Da Prada 3 , K. Biziere ${ }^{3}$, G. R. McClelland ${ }^{4}$, V.L. Jamieson ${ }^{4}$, N. D. Wood ${ }^{4}$ and R. S. J. Frackowiak ${ }^{2}$ \\ ${ }^{1}$ MRC Cyclotron Unit, Hammersmith Hospital, London U. K. and Royal Free Hospital and School of Medicine, London U. K. \\ ${ }^{2}$ MRC Cyclotron Unit, Hammersmith Hospital, London U.K. \\ ${ }^{3}$ Pharmaceutical Research Department, F. Hoffmann-La Roche Ltd, Basel, Switzerland \\ ${ }^{4}$ Clinical Pharmacology Unit. Roche Products Ltd., Welwyn Garden City, Herts., U. K.
}

Received: May 29, 1990/Accepted in revised form: October 4, 1990

Summary. Eight normal subjects ( 3 females and 5 males) were studied using intravenous $\mathrm{L}-\left[{ }^{11} \mathrm{C}\right]$ deprenyl and positron emission tomography. In a single blind study one subject received tracer alone, one subject received an oral pre-dose of $20 \mathrm{mg}$ of L-deprenyl and 6 subjects received oral pre-doses of 10 to $50 \mathrm{mg}$ of a novel reversible MAO-B inhibitor (Ro 19-6327). Dynamic PET scans beginning $12 \mathrm{~h}$ after the oral dose were collected over $90 \mathrm{~min}$ and arterial blood was continuously sampled. Data analysis was modelled for two tissue compartments and using an iterative curve fitting technique the value of the rate constant for irreversible binding of $\mathrm{L}-\left[{ }^{11} \mathrm{C}\right]$ deprenyl to MAO-B (k3) in whole brain was obtained for each subject.

The dose response curves obtained indicated that a dose of at least $0.48 \mathrm{mg} \cdot \mathrm{kg}^{-1}$ of Ro 19-6327 was necessary for $>90 \%$ decrease in whole brain $\mathrm{k} 3$. Inhibition of $\mathrm{MAO}-\mathrm{B}$ in platelets isolated from blood samples taken at the time of scanning correlated strongly with decrease in whole brain $\mathrm{k} 3(r=0.949)$.

The results indicate that PET can be used to determine the dose of Ro $19-6327$ necessary to inhibit $>90 \%$ of brain MAO-B. This technique is an attractive alternative to traditional large scale patient-based dose-finding studies. Moreover it is shown that inhibition of platelet MAO-B can be used as a marker for central MAO-B inhibition with Ro 19-6327.

Key words: Monoamine oxidase type B, Positron emission tomography, Ro 19-6327, Pharmacodynamics

The MPTP model of Parkinson's Disease (PD) suggests that monoamine oxidase may elaborate environmental toxins and, with free radical formation, may play a central role in the oxidative mechanisms which perhaps predispose to nigro-striatal degeneration [1]. L-deprenyl has been used to treat patients with PD [2] and was recently shown to slow disease progression [3]. The preliminary results of a major trial confirm that $10 \mathrm{mg} / \mathrm{day}$ delays the onset of disability requiring L-Dopa medication associated with early and untreated PD [4]. Ro 19-6327 (N-(2- aminoethyl)-5-chloro-2-pyridine carboxamide $\mathrm{HCl}$ ) is a reversible, highly selective inhibitor of MAO-B [5]. It is a substrate for MAO-B on human platelet and brain membranes and is thought to be converted by oxidative deamination to an intermediate which then inhibits reversibly the MAO-B on its active site [6]. Due to its potent inhibition of MAO-B, Ro 19-6327 prevents (in mice) the neurotoxicity caused by 1-Methyl-4-Phenyl-1,2,3,6,tetrahydropyridine (MPTP) [7].

In this study, rather than using a time consuming and expensive dose-finding study in parallel groups of patients, PET has been used to determine the minimum dose of Ro 19-6327 necessary to inhibit $>90 \%$ of brain MAO$B$ in normal subjects prior to clinical trials in phase II of development.

\section{Subjects and methods}

\section{Subjects}

Eight healthy volunteers between the ages of 55 and 71 were studied. Health was assessed by medical history, full clinical examination, haematological and biochemical profile and urinalysis. Older subjects were specifically chosen as being representative of the target population of Parkinsonian patients and in view of the known increase with age of brain MAO-B content. Demographic details of the subjects are shown in Table 1 . All subjects gave informed written consent and local ethics committee approval was granted.

\section{Study protocol}

Six subjects received a single oral dose of between 10 and $50 \mathrm{mg}$ of Ro 19-6327 and one subject received a single oral dose of $20 \mathrm{mg} \mathrm{L}$ deprenyl (selegiline) $12 \mathrm{~h}$ before PET scanning (Table 1 ).

Previous studies had shown complete inhibition of platelet MAO-B by only $5 \mathrm{mg}$ of Ro 19-6327, the duration of maximum inhibition being dose dependent [8], and were a guide to the likely required dose for inhibition of brain MAO-B. PET scans were performed on the CTI 931/08/12 (CTI Inc., Knoxville, Tennessee, USA) scanner at the MRC Cyclotron Unit. The performance of this scanner has been described elsewhere [9]. 
Table 1. Details of the 8 subjects studied

\begin{tabular}{llllll}
\hline $\begin{array}{l}\text { Subject } \\
\text { no. }\end{array}$ & Age & Sex & $\begin{array}{l}\text { Weight } \\
(\mathrm{kg})\end{array}$ & $\begin{array}{l}\text { Dose of } \\
\text { Ro 19-6327 } \\
(\mathrm{mg})\end{array}$ & $\begin{array}{l}\text { Dose of } \\
\text { Ro 19-6327 } \\
(\mathrm{mg} / \mathrm{kg})\end{array}$ \\
\hline 1. & 59 & $\mathrm{M}$ & 74 & 0 & 0.00 \\
2. & 55 & $\mathrm{M}$ & 88 & 10 & 0.11 \\
3. & 70 & $\mathrm{M}$ & 85 & 20 & 0.24 \\
4. & 71 & $\mathrm{~F}$ & 55 & 15 & 0.27 \\
5. & 67 & $\mathrm{~F}$ & 62 & 25 & 0.41 \\
6. & 63 & $\mathrm{~F}$ & 53 & 25 & 0.48 \\
7. & 55 & $\mathrm{M}$ & 73 & 50 & 0.69 \\
8. & 70 & $\mathrm{M}$ & 88 & L-Deprenyl pre-dose (20 mg) \\
\hline
\end{tabular}

Subjects were positioned in the scanner with the orbito-meatal line parallel to the detectors. An individual moulded expanded polystyrene head support was used in each case. A $22 \mathrm{G}$ cannula was inserted into the radial artery after establishing patent collateral circulation and after subcutaneous infiltration with $1 \%$ bupivacaine (Marcain). A $10 \mathrm{~min}$ transmission scan for attenuation correction was collected using a retractable ${ }^{68} \mathrm{Ga} /{ }^{68} \mathrm{Ge}$ ring source. All 8 subjects received bolus intravenous injections of saline solutions of $\mathrm{L}-\left[{ }^{11} \mathrm{C}\right]$ deprenyl $($ mean $=8.23 \mathrm{mCi}, \mathrm{SD}=3.06)$ at the start of the scan. $\mathrm{L}$ $\left[{ }^{11} \mathrm{C}\right]$ deprenyl was prepared by alkylation of the $\mathrm{N}$-demethyl compound with ${ }^{11} \mathrm{C}$ methyl iodide. Specific radioactivities were 70 to $340 \mathrm{mCi} \cdot \mu \mathrm{mol}^{-1}$ and weights of drug injected were 6.2 to $17.1 \mu \mathrm{g}$. Dynamic scans were collected from the time of injection and for a period of 90 minutes, divided into 48 time frames. Frame length was increased from $5 \mathrm{~s}$ initially to $10 \mathrm{~min}$ at the end of the study.

Blood was continuously sampled from the arterial cannula at $5 \mathrm{ml} \cdot \mathrm{min}^{-1}$ for at least $10 \mathrm{~min}$ but was stopped at this point in the 3 lighter subjects. In the remaining subjects sampling continued up to $90 \mathrm{~min}$ at $2.5 \mathrm{ml} \cdot \mathrm{min}^{-1}$. The system used for continuous selective detection of positrons in blood has been described before [10]. Samples were taken at $5,10,15$ and $20 \mathrm{~min}$ for $\mathrm{L}-\left[{ }^{11} \mathrm{C}\right]$ deprenyl metabolite analysis. Calibration samples were taken for whole blood and plasma activity at regular intervals between 5 and $90 \mathrm{~min}$. Samples for plasma levels of Ro 19-6327 and for the estimation of platelet MAO$\mathrm{B}$ activity were taken at $.5,1,2,3,4,6,8,123 / 4$ and $24 \mathrm{~h}$ post oral predose. Platelet MAO-B activity was measured radiochemically.

\section{Metabolite analysis}

The analytical procedure described is a modification of a method originally reported for $\left.{ }^{11} \mathrm{C}\right] \mathrm{Carfentanil} \mathrm{[11].} \mathrm{Arterial} \mathrm{blood} \mathrm{samples}$ $(15 \mathrm{ml})$ were taken at $5,10,15$ and $20 \mathrm{~min}$ in heparinised syringes after $\mathrm{L}-\left[{ }^{1{ }^{1}} \mathrm{C}\right]$ deprenyl injection. Cell free plasma was obtained by centrifugation and processed using a solid phase extraction procedure before HPLC analysis.

Two $C_{18}$ Sep-Pak cartridges (Waters Associates) in series were activated using methanol $(5 \mathrm{ml})$ and further washed with ammonium formate solution $(10 \mathrm{ml}, 0.1 \mathrm{M})$. Cell free plasma $(5 \mathrm{ml})$ spiked with cold L-deprenyl $(200 \mu \mathrm{g})$ as carrier was passed slowly through the Sep-Paks which were subsequently washed with ammonium formate solution $(50 \mathrm{ml}, 0.1 \mathrm{M})$ to remove residual proteins. In control experiments where whole blood was spiked with $\mathrm{L}-\left[{ }^{11} \mathrm{C}\right]$ deprenyl $(100 \mu \mathrm{Ci})$ and cold L-deprenyl $(1 \mathrm{mg})$, greater than $98 \%$ of the total plasma radioactivity was retained on the Sep-Paks.

The ${ }^{11} \mathrm{C}$-activity retained on the Sep-Paks was eluted using methanol $(4 \mathrm{mI})$. More than $95 \%$ of the radioactivity was removed from the Sep-Paks using this procedure. Ammonium formate $(0.1 \mathrm{M})$ was then added to the methanol eluate in order to adjust the composition to that of the HPLC mobile phase. One $\mathrm{ml}$ of this solution was then injected onto a reverse phase HPLC column (" $\mu$-Bondapak", particle size $10 \mu \mathrm{m}, 30 \mathrm{~cm} \times 3.9 \mathrm{~mm}$ internal diameter, Waters Associates) eluted at $3.0 \mathrm{ml} \cdot \mathrm{min}^{-1}$ with a mixture of methanol and ammonium formate $(0.1 \mathrm{M})$ [65:35]. The eluent was monitored for $\mathrm{UV}$ absorbance $(254 \mathrm{~nm}$ ) and radioactivity using a sensitive NaI detector. The eluate from the HPLC column was collected $(0.5 \mathrm{ml}$ fractions) using a fraction collector and fractions counted on a Gamma counter (LKB Pharmacia). The radioactivity in fractions collected for a given HPLC injection was plotted as a function of time and the ratio of unchanged $\mathrm{L}-\left[{ }^{11} \mathrm{C}\right]$ deprenyl to $\left[{ }^{11} \mathrm{C}\right]$ metabolites thus determined. This data was then used to determine the percentage of total activity represented by $\mathrm{L}-\left[{ }^{11} \mathrm{C}\right]$ deprenyl in plasma at a given time point.

\section{Estimation of platelet $M A O-B$ activity}

A $10 \mathrm{ml}$ venous blood sample was collected via an $18 \mathrm{G}$ cannula in a $10 \mathrm{ml}$ plastic syringe containing $1 \mathrm{ml}$ of an EDTA solution $(1 \%$ in saline). After gentle shaking the blood sample was transferred to a polystyrene tube and centrifuged at room temperature for $15 \mathrm{~min}$ at $200 \mathrm{xg}$. The resulting platelet rich plasma (PRP) was transferred to a polyethylene tube using a plastic pipette, avoiding carry-over of erythrocytes. The PRP sample was then centrifuged for $10 \mathrm{~min}$ at $3000 \mathrm{xg}$ at $4^{\circ} \mathrm{C}$. The remaining pellet was washed in the polyethylene tube with $2 \mathrm{ml}$ of ice-cold modified Tyrode. The washed pellets were sedimented by centrifugation and the washing procedure repeated for a second time. The supernatant was discarded and the platelet pellets stored at $-20^{\circ} \mathrm{C}$ until MAO-B activity was assayed.

For the MAO-B assay the platelet pellet was suspended in $300 \mu \mathrm{l}$ saline and was lysed by addition of $2.7 \mathrm{ml} 0.1 \mathrm{M}$ potassium phosphate buffer, $\mathrm{pH} 7.4$ and vigorous vortexing. MAO-B activity was determined by adding to $15 \mathrm{ml}$ glass tubes the following incubation mixture: $50 \mu$ platelet lysate, $200 \mu$ l potassium phosphate buffer $0.5 \mathrm{M}, \mathrm{pH} 7.4,0.5 \mu \mathrm{l}{ }^{14} \mathrm{C}$-2-phenylethylamine $\left({ }^{14} \mathrm{C}-\mathrm{PEA}\right.$, Amersham $\left.\mathrm{UK}, 60 \mathrm{Ci} \cdot \mathrm{mmol}^{-1}\right)$ and $49.5 \mu \mathrm{l}$ unlabelled PEA to yield a final PEA concentration of $0.02 \mathrm{mmol} \cdot \mathrm{l}^{-1}$. After incubation of this mixture for 10 min at $37^{\circ} \mathrm{C}$ under continuous shaking, the reaction was stopped by the addition of $200 \mu \mathrm{l} 2 \mathrm{~N} \mathrm{HCl}$. The deaminated products were extracted into $5 \mathrm{ml} \mathrm{n}$-heptane by vigorous shaking for $10 \mathrm{~min}$ at room temperature. After low speed centrifugation, the aqueous bottom phase was frozen in dry ice/petrolether, and the organic phase poured into counting vials. After addition of $5 \mathrm{ml}$ of Bio-Fluor (NEN) the radioactivity was counted by liquid scintillation spectrometry (counting efficiency $90-92 \%$ ).

\section{Image analysis and modelling of data}

The L- $\left[{ }^{11} \mathrm{C}\right]$ deprenyl scans were analysed using image analysis software (Analyze version 2.0, Biodynamics Research Unit, Mayo Foundation, USA) on Sun 3/60 Workstations. The details of the quantitative analysis will be described elsewhere. Whole brain regions of interest were identified for each scan on 15 planes. Average values of activity for each of these regions were calculated. Time activity curves were plotted for each subject and the data were analysed using the arterial plasma curve, corrected for metabolites and dispersion, as the indicator of the input function to the tissue. The plasma to whole blood ratio time course obtained from the calibration samples was fitted to a multiexponential function. This function was in turn used to transform the whole blood time activity curve into a plasma curve. Subsequently the level of metabolites obtained from the metabolite samples was fitted to a single exponential. This function was used to extract the true input function of unchanged L$\left.{ }^{[1} \mathrm{C}\right]$ deprenyl from the plasma curve.

The kinetics of brain $\mathrm{L}-\left[{ }^{11} \mathrm{C}\right]$ deprenyl were modelled using the 3 compartments shown in Fig. 1. The model consists of a vascular (plasma) compartment and two tissue compartments that correspond to (a) free and non-specifically bound tracer and (b) enzyme bound tracer. Three rate constants were used to describe tracer uptake. $\mathrm{K} 1$ and $\mathrm{k} 2$ are the constants for transport in and out of the tissue space respectively, and $\mathrm{k} 3$ is the constant for binding to the MAO-B. The rate constant $\mathrm{k} 3$ for an irreversible inhibitor, if accurately 


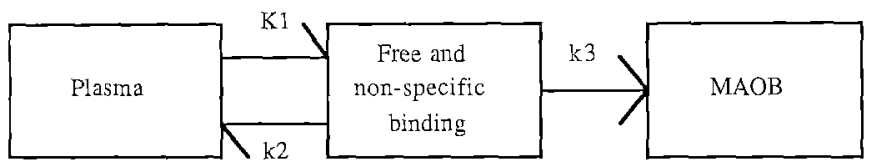

Compartment 1

Compartment 2

Compartment 3

Fig. 1. Schematic representation of the 3-compartment model. The constants $\mathrm{k} 1, \mathrm{k} 2$ and $\mathrm{k} 3$ are the first order rate constants for transport of tracer among the compartments

measured, gives an index of enzyme concentration because $\mathrm{k} 3=\mathrm{ka}$ $\mathrm{x}$ available binding sites, with $\mathrm{ka}$ (the association rate constant of ligand binding to enzyme) assumed to be invariant at trace concentrations. Thus $\mathrm{k} 3$ is a more direct estimate of MAOB binding than other methods of analysis especially those which include a blood flow component and may therefore be confounded in studies of drugs that affect perfusion. Binding of $\left.\mathrm{L}-{ }^{[11} \mathrm{C}\right]$ deprenyl is essentially irreversible [12] and hence there is no 44 (rate constant for dissociation from $\mathrm{MAO}-\mathrm{B})$.

\section{Results}

For all doses of Ro $19-6327$ there was virtually $100 \%$ inhibition of platelet MAO-B up to $4 \mathrm{~h}$ post-dose. After this time there was a dose related recovery of MAO-B activity, which for the high doses was not completely normalised at $24 \mathrm{~h}$ post-dose, when the final sample was taken. At $123 / 4 \mathrm{~h}$ after drug ingestion the effective dose for $50 \%$ inhibition $\left(\mathrm{ED}_{50}\right.$ ) was between 0.11 and $0.27 \mathrm{mg} \cdot \mathrm{kg}^{-1}$ (Table 2).

Following injection of the $\mathrm{L}-\left[{ }^{11} \mathrm{C}\right]$ deprenyl, radioactivity rapidly entered the brain. In the subject who received no pre-treatment, activity remained at a high level throughout the study due to the irreversible nature of the tracer-enzyme interaction (Fig.2). Plasma clearance of total radioactivity was rapid (Fig. 2). The amount of unchanged tracer in plasma declined to $26 \%$ in the first $15 \mathrm{~min}$ as determined by HPLC. In the subjects pre-dosed with either unlabelled l-deprenyl or $>0.41 \mathrm{mg} \cdot \mathrm{kg}^{-1}$ of Ro 19-6327 there was total washout of the tracer from brain, reflecting extensive central enzyme blockade. Initial extraction of the tracer was not affected by the predose (Fig. 3).

Values of $\mathrm{k} 3$ showed a steep decrease with increasing dose of Ro 19-6327 and the highest dose given was as ef-

Table 2. Platelet MAO-B activity and \% inhibition for the eight subjects

\begin{tabular}{|c|c|c|c|}
\hline $\begin{array}{l}\text { Dose of } \\
\text { Ro } 19-6327 \\
\left(\mathrm{mg} \cdot \mathrm{kg}^{-1}\right)\end{array}$ & $\begin{array}{l}\text { Platelet MAO-B } \\
\text { activity pre-dose } \\
\text { (nmol } \mathrm{h}^{-1} \text {. } \\
\mathrm{mg}^{-1} \text { prot.) }\end{array}$ & $\begin{array}{l}\text { Platelet MAO-B } \\
\text { activity at time of } \\
\operatorname{scan} \text { (nmol } \cdot \mathrm{h}^{-L} \text {. } \\
\mathrm{mg}^{-1} \text { prot.) }\end{array}$ & $\begin{array}{l}\% \text { Platelet } \\
\text { MAO-B } \\
\text { inhibition at } \\
\text { time of scan. }\end{array}$ \\
\hline 0.00 & 14.4 & 13.0 & 09.3 \\
\hline $0.11^{a}$ & 13.6 & 8.88 & 34.6 \\
\hline 0.24 & 14.0 & 6.62 & 52.8 \\
\hline 0.27 & 20.6 & 8.07 & 60.8 \\
\hline 0.41 & 17.4 & 2.87 & 83.9 \\
\hline $0.48^{\mathrm{b}}$ & 24.9 & 4.03 & 83.5 \\
\hline 0.69 & 26.8 & 2.67 & 90.1 \\
\hline Deprenyl $20 \mathrm{mg}$ & 16.6 & 0.03 & 99.8 \\
\hline
\end{tabular}

${ }^{a}$ data limited by interrupted blood sampling

b low injected activity $(2.40 \mathrm{mCi})$

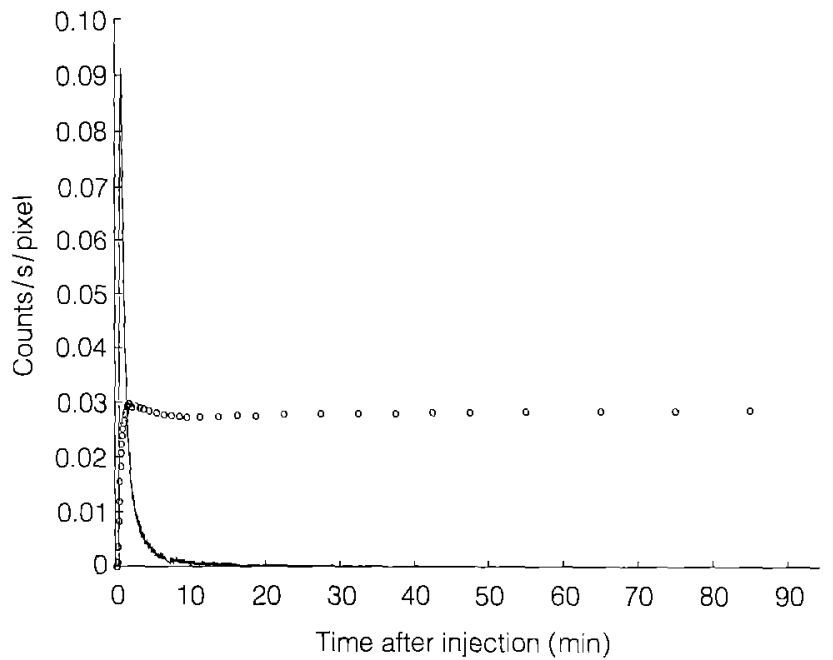

Fig.2. Time activity curves for whole brain (circles) and metabolite corrected plasma (solid) following injection of $\mathrm{L}-\left[{ }^{11} \mathrm{C}\right]$ deprenyl without predosing (subject 1)

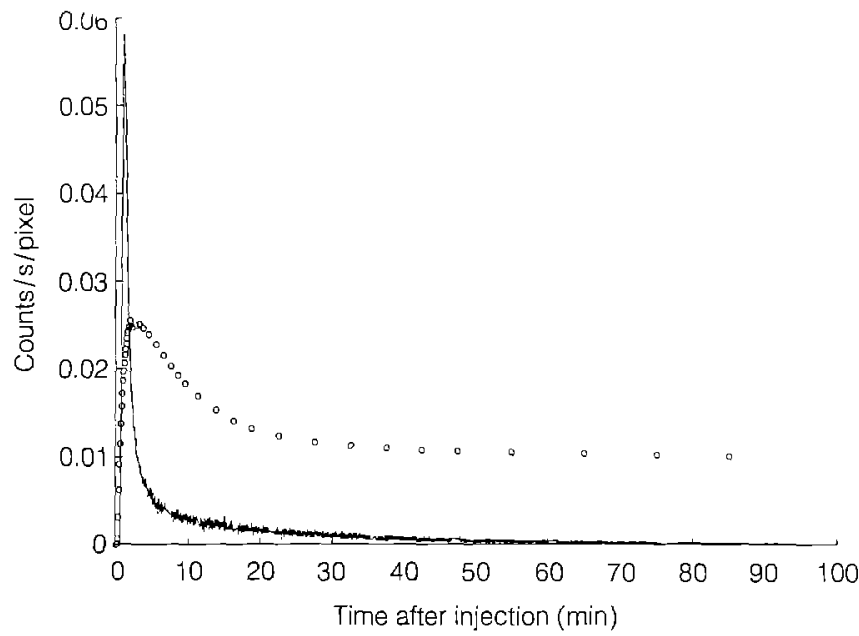

Fig. 3. Time activity curves for whole brain (circles) and metabolite corrected plasma (solid) following injection of $\mathrm{L}-\left[{ }^{11} \mathrm{C}\right]$ deprenyl with predose of Ro 19-6327 (subject 7)

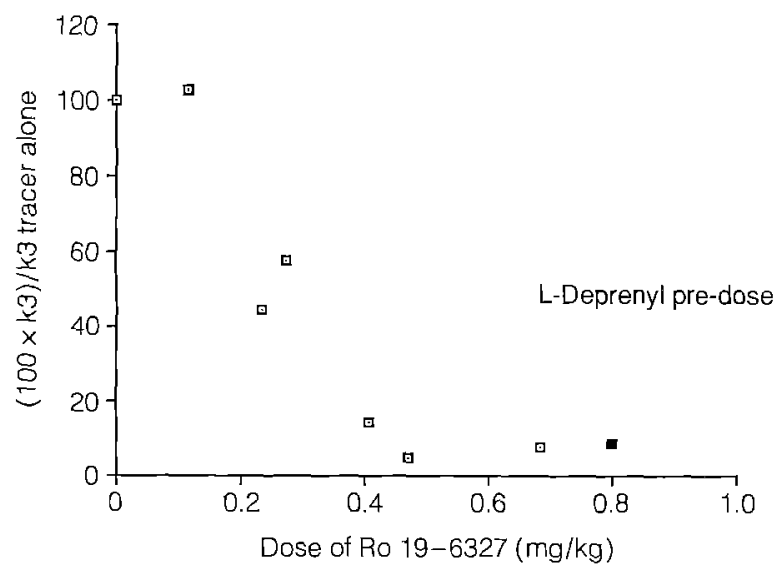

Fig. 4. Whole brain dose response curve $(100 \% \mathrm{k} 3 / \mathrm{k} 3$ (tracer alone\}) vs dose of Ro $19-6327$ ( $\mathrm{mg} / \mathrm{kg}$ ) 
Table 3. Values of $\mathrm{k} 3$ and decrease in $\mathrm{k} 3$ expressed as a percentage of tracer alone $\mathrm{k} 3$ for the eight subjects

\begin{tabular}{llc}
$\begin{array}{l}\text { Dose of } \\
\text { Ro 19-6327 } \\
\left(\mathrm{mg} \cdot \mathrm{kg}^{-1}\right)\end{array}$ & $\begin{array}{l}\mathrm{k} 3 \text { for whole } \\
\text { brain ROI } \\
\left(\mathrm{min}^{-1}\right)\end{array}$ & $\begin{array}{l}\text { decrease } \\
\text { in brain } \mathrm{k} 3 . \\
(\% \text { tracer alone) }\end{array}$ \\
\hline 0.00 & 0.344 & 00.0 \\
$0.11^{\text {a }}$ & 0.353 & -02.62 \\
0.24 & 0.152 & 55.8 \\
0.27 & 0.198 & 42.4 \\
0.41 & 0.051 & 85.2 \\
$0.48^{b}$ & 0.017 & 95.1 \\
0.69 & 0.028 & 91.9 \\
Deprenyl 20 mg & 0.030 & 91.3 \\
\hline
\end{tabular}

a data limited by interrupted blood sampling

${ }^{b}$ low injected activity $(2.40 \mathrm{mCi})$

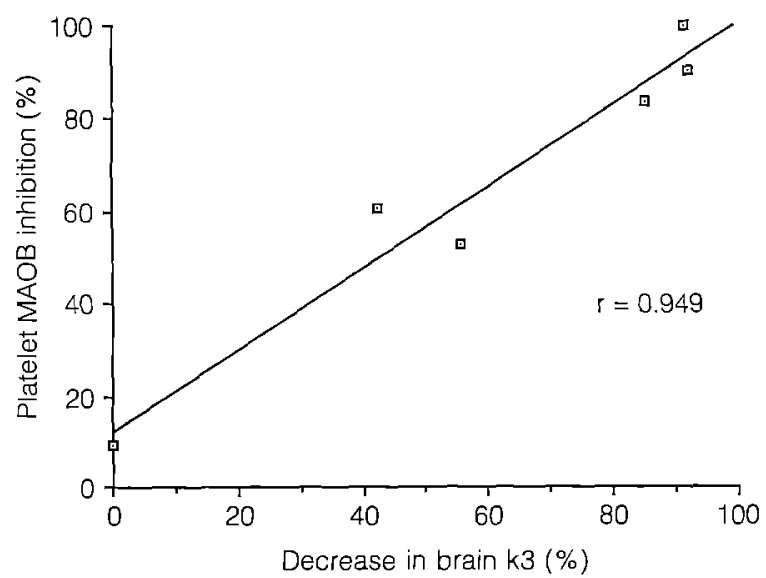

Fig. 5. \% Platelet MAO-B inhibition vs \% decrease brain $\mathrm{k} 3$. The 2 subjects with limited data have been omitted $(r=0,949)$

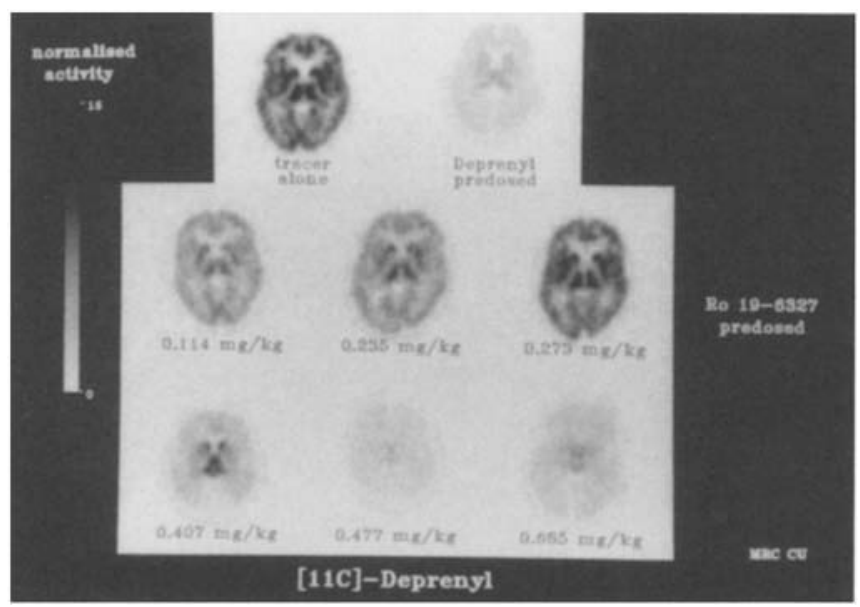

Fig.6. PET images from comparative slices for each subject with brain activity normalised for integrated plasma activity. The images are summated from the dynamic scans collected between 10 and 90 min after injection of $\mathrm{L}-\left[{ }^{11} \mathrm{C}\right]$ deprenyl

fective a blocker as unlabelled L-deprenyl (Fig. 4). A dose of $0.48 \mathrm{mg} \cdot \mathrm{kg}^{-1}$ of Ro $19-6327$ produced at least $90 \%$ decrease in brain $\mathrm{k} 3$ (Table 3 ). Fig. 5 shows the correlation of $\%$ decrease in brain $\mathrm{k} 3$ for $\mathrm{L}-\left[{ }^{11} \mathrm{C}\right]$ deprenyl in the presence of Ro 19-6327 with platelet MAO-B inhibition determined at the scan time. The correlation coefficient is
0.949. Fig.6 shows PET images from comparative slices for each subject with brain activity normalised for integrated plasma activity.

\section{Discussion and conclusions}

In vivo studies of monoamine oxidase in man have been made possible by the development of irreversible "suicide" inhibitors of MAO which inhibit selectively only one type of MAO when administered in low doses. Clorgyline and L-deprenyl are inhibitors of MAO-A and $\mathrm{MAO}-\mathrm{B}$ respectively and can be labelled at the $\mathrm{N}$-methyl position with ${ }^{11}$ Carbon, a nuclide which decays by positron emission with a half life of 20.4 minutes. PET studies using these ${ }^{11} \mathrm{C}$ tracers have shown an anatomical distribution of activity which parallels the distribution of MAO in autopsy material [13]. PET has also been used to measure functional MAO activity in man and to measure turnover rates in primates $[13,14]$. The use and dose response profile of MAO-B inhibitors is under close scrutiny in Parkinson's Disease, with particular interest in highly selective, reversible inhibitors such as Ro 19-6327 which does not show the tyramine pressor effect seen with higher doses of less selective irreversible inhibitors [15].

Prior to the development of quantitative imaging techniques, in vivo assessment of certain drug responses in the CNS such as enzyme inhibition or receptor occupancy relied heavily on analogy with simpler tissues. Of the peripheral "models" of the CNS platelets have been one of the most frequently and extensively investigated. The finding that Ro 19-6327 inhibits platelet MAO-B in humans indicates that the drug is an MAO-B inhibitor in man. In isolation, this information says nothing about whether the drug crosses the blood brain barrier or what doses are required to obtain maximal inhibition in the brain. Attempts to directly correlate platelet MAO-B activity with activity in normal brain material obtained either post-mortem [16] or during neurosurgery [17] have failed. We have performed platelet sampling in conjunction with PET measurements to test the validity of using platelet $\mathrm{MAO}-\mathrm{B}$ assays as a model for brain MAO-B activity.

Using PET we have confirmed that Ro 19-6327 crosses the blood-brain barrier and causes dose dependent inhibition of brain MAO-B. We have also shown that inhibition of the peripheral platelet MAO-B by Ro 196327 can be considered a good model for monitoring brain $\mathrm{MAO}-\mathrm{B}$ inhibition by this drug. The increasing interest in the use of MAO inhibitors in the treatment of Parkinson's Disease (PD), Senile Dementia of the Alzheimer Type and Depressive Illness indicates the need for accurate determination in vivo of brain MAO activity.

Efficacy of an MAO-B inhibitor in the prevention of progression of PD can only reasonably be judged after one year of treatment and with large numbers of patients per treatment group. On theoretical grounds, the hypothesis in $\mathrm{PD}$ which implicates monoamine oxidase type $\mathrm{B}$ in the neurodegenerative mechanism would suggest that the more MAO-B is inhibited by a drug, the greater the protective effect. Therefore, a traditional dose-finding study would require parkinsonian patients to be given the hig- 
hest tolerated dose of Ro 19-6327 for one year with the attendant risks of inducing side effects within this time. The present study shows how PET may be used, possibly as an alternative to time consuming and expensive dose-finding studies in parallel groups of patients, to determine the dose of a MAO-B inhibitor, in this case Ro 19-6327, necessary to inhibit $>90 \%$ of brain MAO-B.

This technique could be extended to other therapeutic areas. For example, in the case of the benzodiazepines it is unknown how much receptor occupancy is needed to obtain an anxiolytic effect in humans. However, for each of the benzodiazepines on the market the anxiolytic dose is known. Using PET and ${ }^{11} \mathrm{C}$-flumazenil it could be seen whether four or five different benzodiazepines produce equivalent receptor occupancy at anxiolytic doses. A new compound could then be rapidly tested for the dose which gives an "anxiolytic" receptor occupancy. A similar strategy could be used for specific monoamine oxidase type A inhibitors, which are being developed as antidepressive drugs, using ${ }^{11} \mathrm{C}$-clorgyline as the PET tracer. The early clinical development of new drugs may therefore soon include, as a matter of course, measures of clinical efficacy in combination with pharmacodynamic studies using PET and suitable tracers to confirm the test drug's penetration of the blood brain barrier and allow accurate quantitation of its action on central enzyme or receptor systems.

Acknowledgements. The authors thank Dr. Ralph Myers for Fig. 5 and the staff of the MRC Cyclotron Unit for their assistance in this study.

C. J.B. is funded by a grant from the Wellcome Trust.

\section{References}

1. Langston JW, Ballard P, Tetrud JW, Irwin I (1983) Chronic parkinsonism in humans due to a product of meperidine. Science 219: $979-80$

2. Birkmayer W, Riederer P (1983) Parkinson's disease. Springer, Vienna

3. Tetrud JW, Langston JW (1989) The effect of deprenyl (selegiline) on the natural history of Parkinson's Disease. Science 245: $519-522$

4. The Parkinson Study Group (1989) Effect of deprenyl on the progression of disability in early Parkinson's Disease. N Engl J Med 321:1364-1371

5. Da Prada M, Kettler R, Keller HH, Burkard WP (1988) Ro 196327, a reversible, highly selective inhibitor of the type $B$ monoamine oxidase, completely devoid of tyramine-potentiating effects: comparison with selegiline. In: Dahlstrom A (ed) Progress in catecholamine research part B: central aspects, Liss, pp 359-363
6. Cesura AM, Galva MD, Imhof R, Picotti GB, Da Prada M(1989) $\left[{ }^{3} \mathrm{H}\right]$ Ro 19-6327: a reversible ligand and affinity labelling probe for monoamine oxidase B. Eur J Pharmacol 162: 457-465

7. Da Prada M, Kettler R, Keller HH, Bonetti EP, Imhof R (1986) Ro 16-6491: a new reversible and highly selective MAO-B inhibitor protects mice from the dopaminergic toxicity of MPTP. In: Yahr MD, Bermann KJ (eds) Advances in neurology, vol 45: Parkinson's disease. Raven Press, New York, p 175

8. Kettler R, DaPrada M (1989) Platelet MAO-B activity in humans and stumptail monkeys; in vivo effects of the reversible MAO-B inhibitor Ro 19-6327. In: Przuntek H, Riederer P (eds) Early diagnosis and preventive therapy in Parkinson's Disease. Springer, New York, pp 213-219

9. Spinks TJ, Jones T, Gilardi MC, Heather JD (1988) Physical performance of the latest generation of commercial positron scanner. IEEE Trans Nucl Sci 35: 721-725

10. Lammertsma AA, Frackowiak RSJ, Hoffman JM, Huang S-C, Weinberg IN, Dahlbom M, MacDonald NS, Hoffman EJ, Mazziotta JC, Heather JD, Forse GR, Phelps ME, Jones T(1989) The $\mathrm{C}^{15} \mathrm{O}_{2}$ build-up technique to measure regional cerebral blood flow and volume of distribution of water. J Cereb Blood Flow Metab 9: 461-470

11. Frost JJ, Douglass KH, Mayberg HS, Dannals RF, Links JM, Wilson HT, Ravert HT, Crozier WC, Wagner HN Jr (1989) Multicompartmental Analysis of $\left[{ }^{11} \mathrm{C}\right]$-Carfentanil Binding to Opiate Receptors in Humans Measured by Positron Emission Tomography. J Cereb Blood Flow Metab 9: 398-409

12. Maycock AL, Abeles RH, Salach JI, Singer TP (1976) The structure of the covalent adduct formed by the interaction of 3-dimethylamino-1-propyne and the flavine of mitochondrial amine oxidase. Biochemistry 15: 114-125

13. Fowler JS, Macgregor RR, Wolf AP, Arnett CD, Dewey SL, Schlyer D, Christman D, Logan J, Smith M, Sachs H, Aquilonius SM, Bjurling P, Halldin C, Hartvig P, Leenders KL, Lundqvist $\mathrm{H}$, Oreland L, Stalnacke C-G, Langstrom B (1987) Mapping human brain monoamine oxidase $\mathrm{A}$ and $\mathrm{B}$ with ${ }^{11} \mathrm{C}$-labelled suicide inactivators and PET. Science 235: 481-485

14. Arnett CD, Fowler JS, Macgregor RR, Schlyer DJ, Wolf AP, Langstrom B, Halldin C (1987) Turnover of brain monoamine oxidase measured in vivo by positron emission tomography using L- $\left[{ }^{11} \mathrm{C}\right]$ Deprenyl. J Neurochem 49: 522-527

15. Schulz R, Antonin K-H, Hoffman E, Jedrychowski M, Nilsson E, Schick C, Bieck PR (1989) Tyramine kinetics and pressor sensitivity during monoamine oxidase inhibition by selegiline. Clin Pharmacol Ther 46: 528-536

16. Winblad B, Gottfries C-G, Oreland L, Wiberg A (1979) Monoamine oxidase in platelets and brains of non-psychiatric and non-neurological geriatric patients. Med Biol 57: 129-132

17. Young WF, Laws ER, Sharbrough FW, Weinshilboum RM (1986) Human monoamine oxidase. Lack of brain and platelet correlation. Arch Gen Psychiatry 43: 604-609

Dr. C. J.Bench

MRC Cyclotron Unit

Hammersmith Hospital

DuCane Road

London W12 OHS, UK 